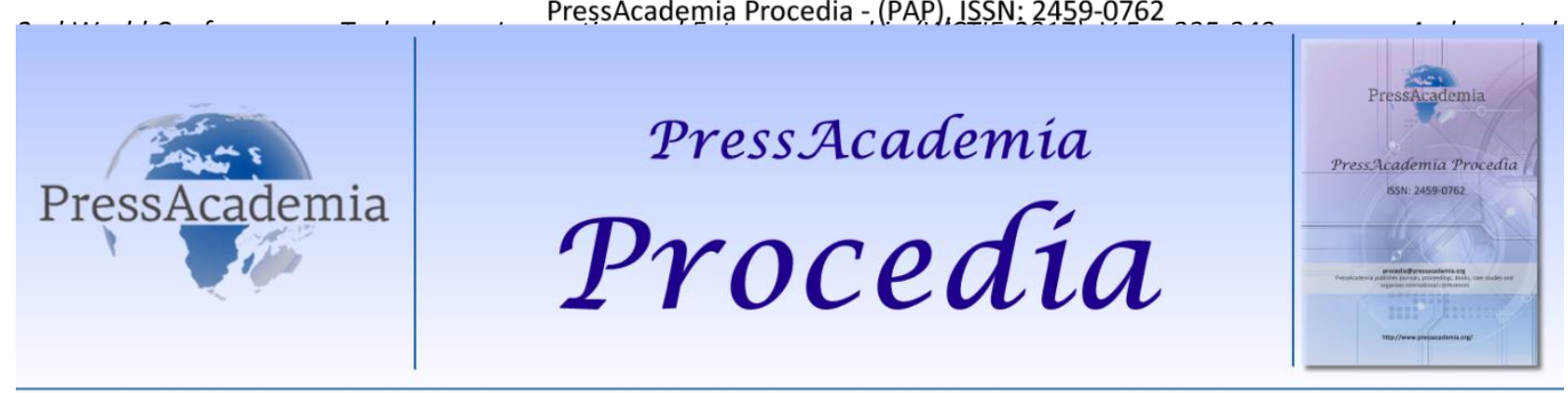

2nd World Conference on Technology, Innovation and Entrepreneurship

May 12-14, 2017, Istanbul, Turkey. Edited by Sefer Şener

\title{
ON THE PREDICTION OF STRUCTURAL REACTIONS TO BIG EARTHQUAKES IN TURKEY
}

\author{
DOI: 10.17261/Pressacademia.2017.608 \\ PAP-WCTIE-V.5-2017(46)-p.335-340 \\ Guvenc Arslan ${ }^{1}$, Diaa Fawzy ${ }^{2}$, Coskun Atay ${ }^{2}$ \\ ${ }^{1}$ Kirikkale University, Ankara, Turkey \\ ${ }^{2}$ Izmir University of Eonomics, Izmir, Turkey
}

\begin{abstract}
The prediction of structural reactions to big earthquakes is vital in giving warnings for potential damages early enough to minimize losses of life and properties. In the current study we describe buildings by fixed construction and environmental related parameters. Our models are based on real data of damaged buildings collected after the occurrence of three big earthquakes in Turkey. We extend our previous work to include the soil type for damaged buildings. We employ different techniques, namely neural networks (NN) and support vector machines (SVM) to improve the prediction accuracy. The results show that support vector machines, and in particular support vector regression gives better results compared to neural networks. Although we only used averages of soil type for each region, we observed that adding soil type has improved accuracy of predictions for building damages. It is to be noted that these types of predictions are important to ensure the serviceability and safety of existing structures. Our models are vital for the authorities to make fast and reliable decisions and can be also used to improve the development of new constructions codes.
\end{abstract}

\section{INTRODUCTION}

Since the formation of the earth, earthquakes have occurred in succession in seismically active areas, resulting in the disappearance of millions of people and buildings. Turkey lies on one of the world's most active regions in terms of earthquakes. Approximately 60,000 people have lost their lives, 125,000 people have been injured and 415,000 buildings have been destroyed in earthquakes in our country during the last 60 years, $96 \%$ of our country's lands show the distribution of the first four earthquake zones and $98 \%$ of the total population live in these regions. Because of these reasons, we should always be ready to earthquakes and earthquake as an important factor should always be taken into account in settlement planning.

The earthquakes in Turkey located in the Alpine-Himalayan earthquake belt are related to the movement of the AfricanArabian plates to the north-northeast direction due to the spreading of the Atlantic Ocean's back toward the two sides. Moreover, the Arabian plate is being pushed to the north and forced to dive under the plate of Eurasia, due to the spread of the sea floor which continues today along the long axis of the Red Sea. Due to this strain, there is an intense jamming effect in the eastern Anatolian region between the Arabian plate and the Eurasian continent. This compression, which has caused major fractures such as the North Anatolian Fault and the Eastern Anatolian Fault, has been going on for millions of years and is the main cause of the earthquakes that we are experiencing today.

The North Anatolian Fault is $1400-1500 \mathrm{~km}$ in length. The Anatolian plate between the North Anatolian Fault and the East Anatolian Fault moves westward at a speed of 13-27 mm per year and in the westernmost direction it is curved to the left to the Crete seduction zone.

In November 1999, a devastating earthquake of 7.2 magnitude occurred at the epicenter of Düzce. The earthquake occurred in the direction of East-West between Akyazı-Bolu Tunnel in the direction of Düzce Fault extending parallel to the North Anatolian Fault. In this earthquake, it is understood that the eastern part of the Düzce Fault, which is broken down during the August 17, 1999 earthquake, is broken up, mainly in the $30 \mathrm{~km}$ segment in the westernmost part. 
In February 2002, a devastating earthquake (USGS Ms: 6.5) struck Afyon in the south east. The earthquake was strongly felt in Konya-Ankara-Eskisehir-Kütahya-Isparta provinces where Sultandağı-Çay-Bolvadin districts of Afyon province were the center. 46 people died in the earthquake, 318 people were injured and 622 buildings were seriously damaged. In large settlements, the most damage occurred in the Çay district, and the Sultandağı and Bolvadin districts also suffered damage. The damage to the rural settlements is concentrated in the villages which are heavily dependent on the provinces of Çay and Sultandağı. The surface fracture developed is faded in the alluvial rust, which consists of marsh at the westernmost end. At the eastern end, the fracture lengths of the bifurcated surface consist of intermittent particles ranging from a few tens of meters to several hundreds of meters and distributed in two main directions. The surface faulting in the Çay district and the parts observed to the east of it were observed in metamorphic foundation rocks. In the Maltepe district, the fracture developed completely in the Pleistocene and Holocene deposits. In the Sultandağı earthquake, although there were large alluvial plains in the fault ceiling block, a few field liquefaction events could be observed. The most prominent example of liquefaction was found in the vicinity of the Çay district of the current bed near the industrial site. Numerous and varied sizes of this area, similar to the liquefaction cone, have observed cone-shaped morphologic sand and gravel pile. The majority of these territories are composed of pebbles and the few are of silt and sandy material. Some of these soil deposits, especially salty material, are notable for their mudflows and offer similarity to liquefaction. It has been reported that the largest structural damage occurred on sandy and marshy grounds where the groundwater level is high.

The vibration-based structural damage detection methods are based on correlating model parameters with the physical properties of the structure. The time history of the measured natural frequency changes can be analyzed and modeled (Friswell and Penny; 1997). Since the natural frequency is a global parameter of the whole structure, these methods can not offer detailed information about local damages. Although the success is shown by the vibration-based methods, they are found to be very sensitive to the measurement noise and to the environmental parameter more than the structural parameters themselves. Housner (1997) has shown that once the data are available for damaged structures, statistical based methods and supervised learning approaches are very promising in detecting damages.

These considerations imply the urgent need for early warning systems. They also show that the ability of predicting future disasters is of great interest to the society. However, predicting future earthquakes is a very complicated task. New methods based on combining shifts in the geomagnetic fields with changes on the ionosphere and shifts of the Earth's crust are found to be very promising (see, e.g., Ruzhin et al. 2014; Duma, G. and Ruzhin, Y. 2003; Davis et al. 1980; Rikitake et al. 1980)

The current work is a continuation of our previous study Fawzy \& Arslan (2015), hereafter called paper I. In our previous work we tried to predict the reaction of buildings to big earthquakes, we trained a neural network model with real data of damaged buildings collected after the occurrence of three big earthquakes Afyon (2002; Mw =6.0), Bingöl (2003; Mw = 6.4) and Düzce (1999; Mw = 7.2). In paper I, we took into account the five basic building parameters, namely, age of the building, number of stories, average floor area, and column area. As an extension of our previous work, we add the average soil type underneath buildings as an extra parameter. The aim of the current study is three folds; (1) extending our previous data set to obtain more statistically reliable results, (2) generating more realistic models by adding the soil type as a parameter, and (3) comparing the results from different mathematical approaches to increase the prediction accuracy. It is also important to mention that the models are based on real data and not on probabilistic models.

\section{METHODOLOGY AND THE PREDICTION MODELS}

Different approaches for developing models to predict the degree of damages of buildings may be considered. In this study we concentrate on neural networks and support vector machines. One of our main goals is to extend our previous work in Fawzy \& Arslan (2015). In this respect we have added more cases to the data set resulting in a total of 58 instances. For a more detailed description of the data set we refer the reader to Fawzy \& Arslan (2015). In this study we also added soil type as a parameter, thus increasing the number of parameters.

\subsection{Input Parameters}

Although there are many factors which affect the degree of damage for buildings we have considered the following basic input parameters in this study:

3. intensity of earthquake,

4. Building type (only reinforced concrete)

5. number of floors,

6. building age,

7. average area,

8. total column area, and

9. soil type. 
By using basic data analysis it can be seen that there is a high correlation between the two input parameters "average area" and "column area" (see Fig. 1). Therefore, we decided to exclude "column area" and to include the ratio of average area / column area as a new parameter, which is denoted as "column index". In this study we also added soil type to our analysis. It is known that soil conditions affect amplitude, frequency and duration of the ground movements (Bol 2012). On the other hand, it is important to mention here that the exact determination of soil type is a difficult task. It may vary drastically even between sub regions of a particular study area. Therefore we decided to use an average soil type indicator for each of the three earthquake regions considered in the current study. The following ordinal variable was used to indicate average soil conditions in the considered regions.
1. Very hard
2. Solid
3. Moderately Solid
4. Loose Ground

Figure 1: Scatter Plot for COL_Area and Avg_Area

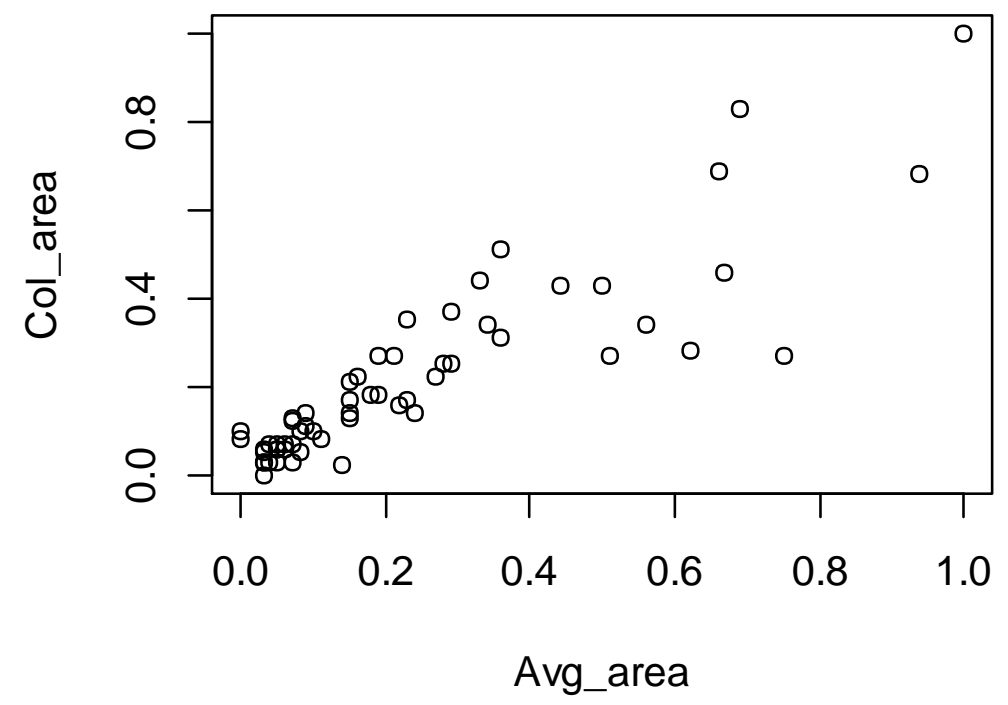

\subsection{Damage Classification}

The calssification of damages we employ for the current study is based on study by Grünthal (1998). Damge levels are divided into the following 5 different categories:

Grade 1: Negligible to slight damage (no structural damage, slight non-structural damage)

Grade 2: Moderate damage (slight structural damage, moderate non-structural damage)

Grade 3: Substantial to heavy damage (moderate structural damage, heavy non-structural damage)

Grade 4: Very heavy damage (heavy structural damage, very heavy non-structural damage)

Grade 5: Destruction (very heavy structural damage)

\subsection{Neural Networks (NN)}

Neural networks learn by training approach similar to their biological counterparts. Although there are different types of learning methods, we concentrate here on the supervised feedforward learning techniques. It should be noted that with enough number of data points used for training of the network and several training cycles an optimum set of weights can be found. The performance function is then computed based on the error between predicted values and the actual cases. For more detailed explanation and information about neural networks the reader is referred to Hornik (1991) and Haykin (1999), among many other references. 


\subsection{Support Vector Machine (SVM)}

Support vector machines (SVM) are one of the state of the art learning algorithms preferred by many researchers in recent years. Classically developed for two-class classification problems and based on the idea of maximum margin classification, they have been extended to more than two-class problems and generalized in various ways. SVMs exploit the idea of mapping the input space into a higher dimensional reproducing kernel Hilbert space in order to obtain a separable space in the new space. Therefore, they are also referred to as kernel machines. SVMs were developed in the framework of statistical learning theory, which was mainly developed by Vapnik and Chervonenkis $(1964,1974,1998)$.

The basic idea of SVMs for classification can also be used for regression. The first step, in general, is to map the input variables into a feature space by a particular map $\phi$. From a given training set of examples $N$ are selected as support vectors. For any given examples $x$ and $x^{\prime}$ in the input space the map $\phi$ produces an inner product, which is denoted by $K\left(x, x^{\prime}\right)=\langle\phi(x)$, $\phi\left(x^{\prime}\right)>$. The output of the SVM is then obtained as $\Sigma \alpha_{i} K\left(x, x_{i}\right)+w_{0}$. For more information on support vector regression the reader is referred to Smola and Schölkopf (2004).

Figure 2: SVM with $n$ Inputs and $N$ Support Vectors

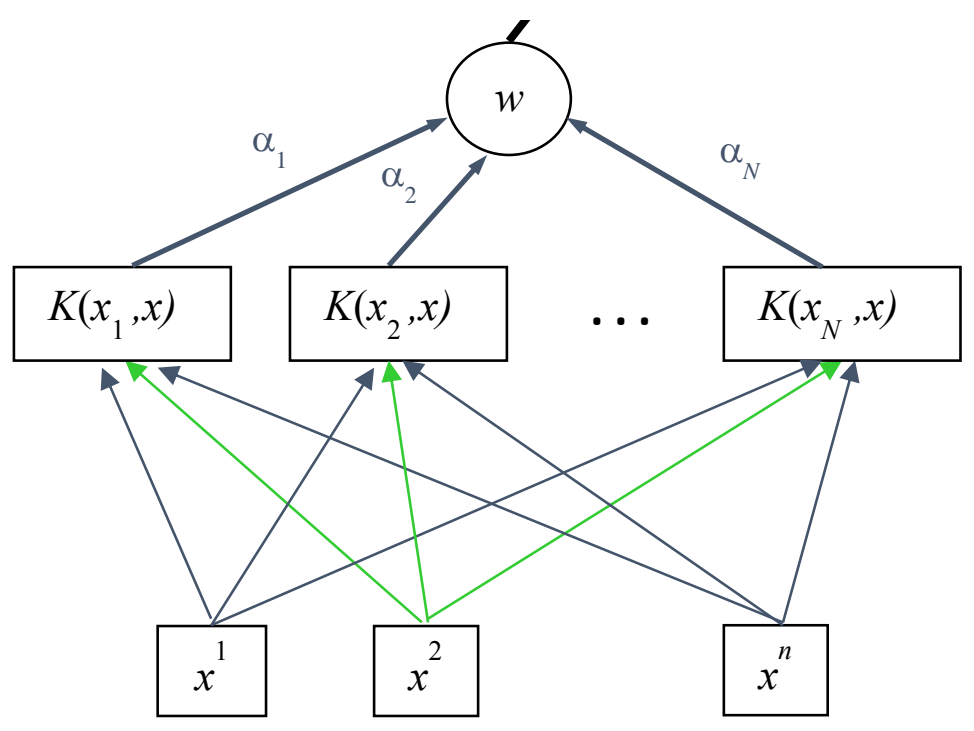

\section{Results and Discussion}

In this study we used a data set consisting of 58 training examples representing data of damaged buildings for three major earthquakes in Afyon, Bingöl and Düzce. 
Figure 3: Neural Network Model with 2 Hidden Layers

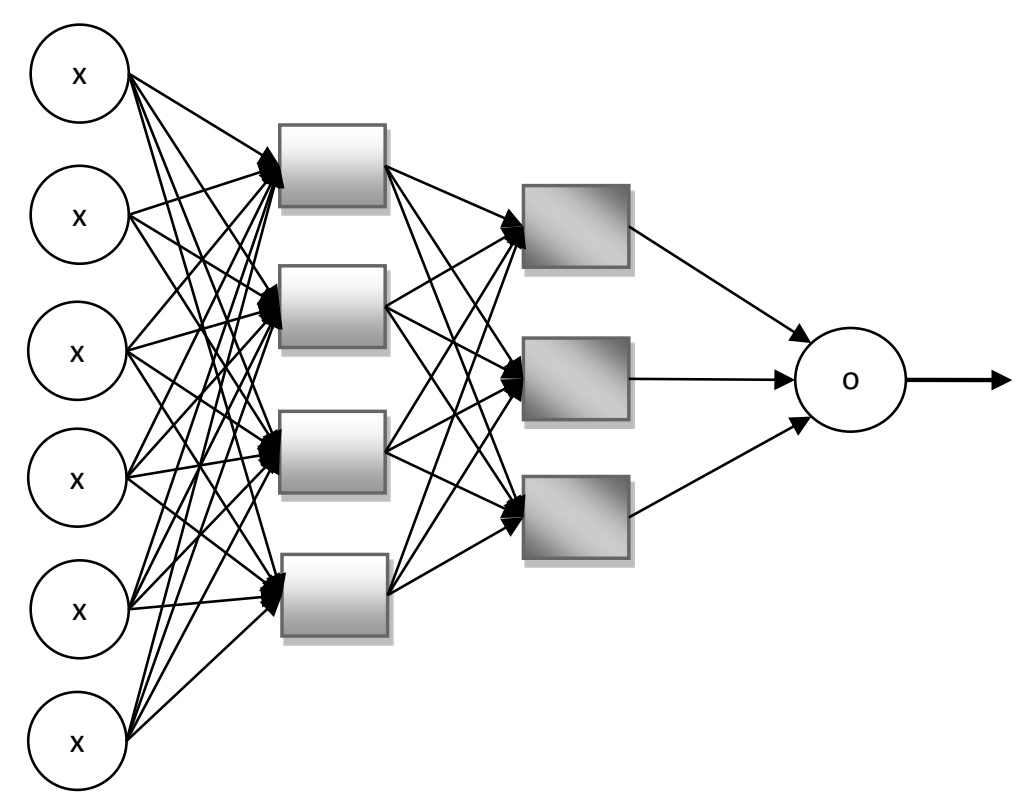

Figure 3 shows the feedforward neural network that we obtained for the earthquake data using Encog software (Heaton, 2015). After trying several two layer models such as five neurons in the first layer and three neurons in the second layer we used the best two layer model structure that we obtained, which is shown in Figure 3. This model has two hidden layers with four and three neurons in the first and second hidden layer, respectively. We note that the training of the neural network takes more time and also gives a training error rate of about $5.75 \%$. The validation chart for this model is given in Figure 4 .

Figure 4: Validation Graph for Neural Network Model

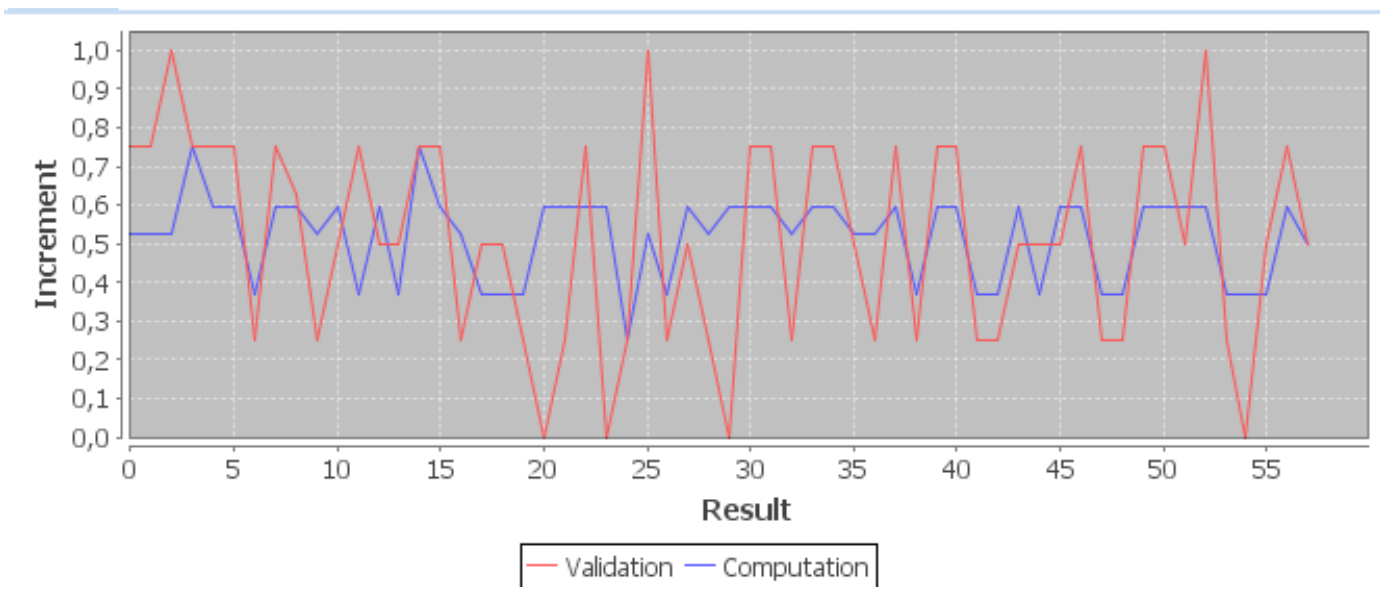

The results show that support vector machines, and in particular support vector regression gives better results compared to neural networks. Although we only used averages of soil type for each region, we observed that adding soil type has improved accuracy of predictions for building damages. Figure 5 shows the results of a support vector regression model implemented in the Encog software (Heaton, 2015). The training error rate for this model is less than $1 \%$. We note also that we used the following input parameters in both models: intensity, number of floors, building age, average area, column index and soil type. It can be seen from Figures 4 and 5 that support vector regression clearly gives better results in terms of accuracy. In addition, it should be noted that the support vector regression model should be preferred because there is no need to determine an appropriate network structure. Only an appropriate kernel has to be determined. In this study we used radial basis functions for the kernel type. 
Figure 5: Validation Graph for Support Vector Regression

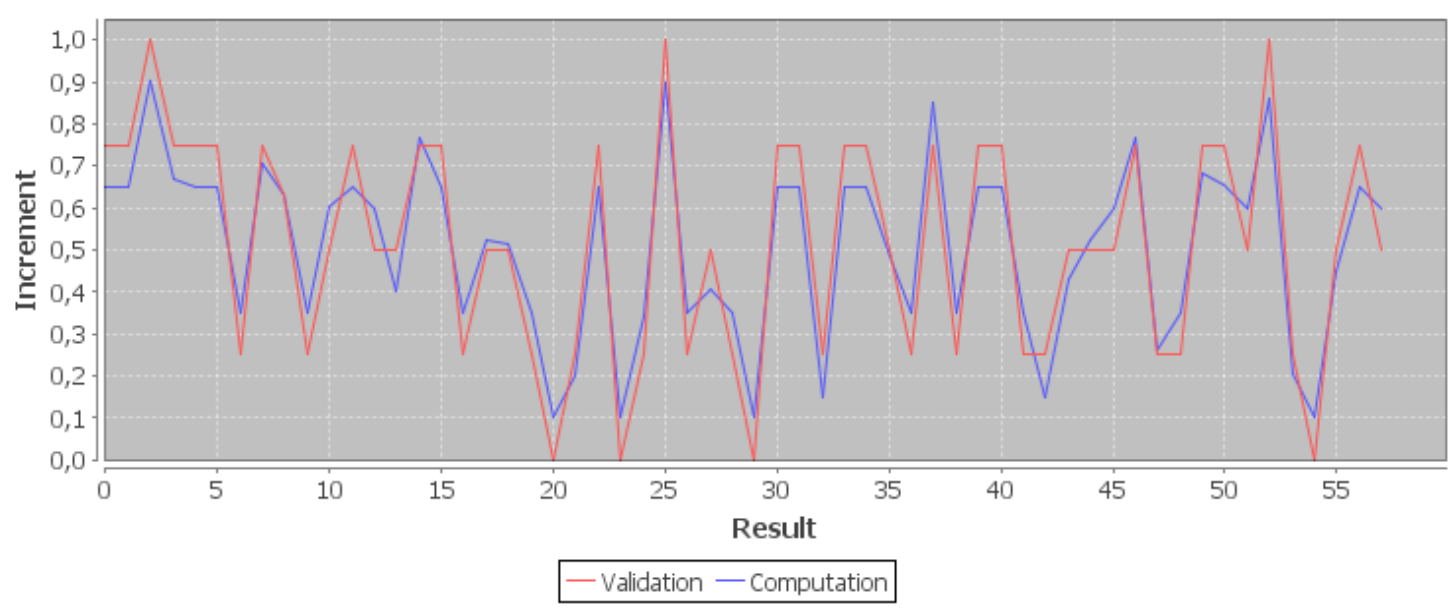

\section{REFERENCES}

1. Bol, E., "Determination of the relationship between soil properties and earthquake damage with the aid of neural networks: a case study in Adapazarı", Turkey, Nat. Hazards Earth Syst. Sci 12: 2965-2975, 2012.

2. Davis, Paul M.; Jakson, David D.; Johnston Malcom J.S.: "Further evidence of localized geomagnetic field changes before the 1974 Thanksgiving Day Earthquake, Hollister, California”, Geophysical Reasearch Letter, Vol. 7, Issue 7 (513-516), 1980.

3. Duma, G. and Ruzhin, Y.: “ Diurnal changes of earthquake activity and geomagnetic Sq-variation”, Natural Hazards and Earth Systems Sciences, 3 (171-177), 2003.

4. Fawzy, D.E. and Arslan, G.; "Development of building damage functions for big earthquakes in Turkey", Procedia - Social and Behavioral Sciences, 195 (2290-2297), 2015.

5. Friswell, M.I., Penny, Jet, and Gravey, SD, " A combined gentic and eigensensitivity algorithm for the location of damage in structure", Computers and Structures, 69: 547-556, 1998.

6. Grünthal, G., (ed.). "European Macroseismic Scale 1998", Cahiers du Centre Européen de Géodynamique et de Séismologie Volume 15, Luxembourg, 1998

7. Housner, G.W., Bergman, L.A., et al. "Structural control: past, present and future", Journal of Engineering Mechanics, 123 (9): 897-971, 1997.

8. Heaton, J., Encog: "Library of Interchangeable Machine Learning Models for Java and C\#”, Journal of Machine Learning Research 16: 1243-1247, 2015.

9. Haykin, S.; “Neural Networks: A Comprehensive Foundation”, Prentice Hall, 1999.

10. Hornik, K.: "Approximation Capabilities of Multilayer Feedforward Networks, Neural Networks", 4(2), 251-257, 1991

11. MTA (Mineral Research \& Exploration General Directorate) mta.gov.tr.

12. Rikitake T., et al.: "Changes in the Geomagnetic Field Associated with Earthquakes in the Izu Peninsula, Japan", Journal of geomagnetism and geoelectricity, Vol. 32, 12 (721-739), 1980.

13. Ruzhin, Yuri; Kamogawa Masashi; Novikov, Victor: "Interrelation of geomagnetic storms and earthquakes: Insight from lab experiments and field observations", 40th COSPAR Scientific Assembly. Held 2-10 August 2014, in Moscow, Russia, Abstract A3.1-68-14

14. Smola, A.J., Schölkopf, B., “A tutorial on support vector regression”, Statistics and Computing 14: 199-222, 2004.

15. Vapnik, V., Chervonenkis, A., "A note on one class of perceptrons, Automation and Remote Control”, 25, 1964.

16. Vapnik, V., Chervonenkis, A., "Theory of Pattern Recognition" [in Russian]. Nauka, Moscow, 1974. (German Translation: Wapnik W. \& Tscherwonenkis A., Theorie der Zeichenerkennung, Akademie-Verlag, Berlin, 1979).

17. Vapnik, V.,"Statistical Learning Theory", John Wiley and Sons, New York, 1998. 